\title{
INCIDENCE OF HEPATOCELLULAR CARCINOMA AND ASSOCIATED RISK FACTORS IN HEPATITIS C-RELATED ADVANCED LIVER DISEASE
}

Anna S. Lok ${ }^{1}$, Leonard B. Seeff ${ }^{2}$, Timothy R. Morgan ${ }^{3}$, Adrian M. Di Bisceglie ${ }^{4}$, Richard K. Sterling ${ }^{5}$, Teresa M. Curto ${ }^{6}$, Gregory T. Everson ${ }^{7}$, Karen L. Lindsay ${ }^{8}$, William M. Lee ${ }^{9}$, Herbert L. Bonkovsky ${ }^{10}$, Jules L. Dienstag ${ }^{11}$, Marc G. Ghany ${ }^{12}$, Chihiro Morishima ${ }^{13}$, Zachary D. Goodman ${ }^{14}$, and the HALT-C Trial Group

${ }^{1}$ Division of Gastroenterology, University of Michigan Medical Center, Ann Arbor, MI

${ }^{2}$ Division of Digestive Diseases and Nutrition, National Institute of Diabetes and Digestive and Kidney Diseases, National Institutes of Health, Department of Health and Human Services, Bethesda, MD

${ }^{3}$ Division of Gastroenterology, University of California - Irvine, Irvine, CA and Gastroenterology Service, VA Long Beach Healthcare System, Long Beach, CA

${ }^{4}$ Division of Gastroenterology and Hepatology, Saint Louis University School of Medicine, St. Louis, MO

${ }^{5}$ Hepatology Section, Virginia Commonwealth University Medical Center, Richmond, VA

${ }^{6}$ New England Research Institutes, Watertown, MA

${ }^{7}$ Section of Hepatology, Division of Gastroenterology and Hepatology, University of Colorado School of Medicine, Denver, CO

${ }^{8}$ Division of Gastrointestinal and Liver Diseases, Keck School of Medicine, University of Southern California, Los Angeles, CA

${ }^{9}$ Division of Digestive and Liver Diseases, University of Texas Southwestern Medical Center, Dallas, TX

${ }^{10}$ Departments of Medicine and Molecular \& Structural Biology and The Liver-Biliary-Pancreatic Center, University of Connecticut Health Center, Farmington, CT

${ }^{11}$ Gastrointestinal Unit (Medical Services), Massachusetts General Hospital and the Department of Medicine, Harvard Medical School, Boston, MA

Address correspondence to: Anna S. Lok, MD, Division of Gastroenterology, University of Michigan Hospitals, 3912 Taubman

Center, SPC 5362, Ann Arbor, MI 48109, Fax: 734-936-7392, aslok@umich.edu.

Dr Bonkovsky's current address is Carolinas medical Center, Charlotte, NC.

*The HALT-C Trial was registered with clinicaltrials.gov (\#NCT00006164).

Financial Disclosures

Financial relationships of the authors with Hoffmann-La Roche, Inc., are as follows:

A.S. Lok is a consultant; T.R. Morgan is consultant, on the speaker's bureau and receives research support; A.M. Di Bisceglie is a consultant, on the speaker's bureau, and receives research support; R.K. Sterling is a consultant, on the speaker's bureau, and receives research support; G.T. Everson is a consultant, on the speaker's bureau, and receives research support; K.L. Lindsay is a consultant and receives research support; W.M. Lee receives research support; H.L. Bonkovsky receives research support. Authors with no financial relationships related to this project are: L.B. Seeff, T.M. Curto, J.L. Dienstag, M.G. Ghany, C. Morishima, and Z.D. Goodman.

Potential investigator conflict of interest had been disclosed to study participants 
${ }^{12}$ Liver Diseases Branch, National Institute of Diabetes and Digestive and Kidney Diseases, National Institutes of Health, Department of Health and Human Services, Bethesda, MD

${ }^{13}$ Virology Division, Department of Laboratory Medicine, University of Washington, Seattle, WA

${ }^{14}$ Division of Hepatic Pathology and the Veterans Administration Special Reference Laboratory for Pathology, Armed Forces Institute of Pathology, Washington, DC

\section{Abstract}

Background and Aims-Although the incidence of hepatocellular carcinoma (HCC) is increasing in the United States, data from large prospective studies are limited. We evaluated the hepatitis $\mathrm{C}$ antiviral long-term treatment against cirrhosis (HALT-C) cohort for the incidence of $\mathrm{HCC}$ and associated risk factors.

Methods-HCV-positive patients with bridging fibrosis or cirrhosis that did not respond to peginterferon and ribavirin were randomized to groups that were given maintenance peginterferon for 3.5 years or no treatment. HCC incidence was determined by Kaplan-Meier analysis and baseline factors associated with HCC were analyzed by Cox regression.

Results-1,005 patients (mean age 50.2 years, $71 \%$ male, $72 \%$ white) were studied; $59 \%$ had bridging fibrosis and $41 \%$ had cirrhosis. During a median follow-up of 4.6 years (maximum 6.7 years), HCC developed in 48 patients (4.8\%). The cumulative 5-year HCC incidence was similar for peginterferon-treated patients and controls, $5.4 \%$ vs. $5.0 \%(\mathrm{p}=0.78)$, and was higher among patients with cirrhosis than those with bridging fibrosis, $7.0 \%$ vs. $4.1 \%$ ( $\mathrm{p}=0.08$ ). HCC developed in eight $(17 \%)$ patients whose serial biopsies showed only fibrosis. A multivariate analysis model comprising older age, black race, lower platelet count, higher alkaline phosphatase, esophageal varices, and smoking was developed to predict the risk of HCC.

Conclusions-We found that maintenance peginterferon did not reduce the incidence of HCC in the HALT-C cohort. Baseline clinical and laboratory features predicted risk for HCC.

Additional studies are required to confirm our finding of $\mathrm{HCC}$ in patients with chronic hepatitis $\mathrm{C}$ and bridging fibrosis.

\section{INTRODUCTION}

Chronic hepatitis $\mathrm{C}$ is a potentially progressive condition, characterized by slowly evolving fibrosis that can culminate in cirrhosis ${ }^{1,2}$. Over time, compensated cirrhosis can advance to decompensated cirrhosis terminating in hepatic failure and death. A common cause for liverrelated death among persons with chronic hepatitis $\mathrm{C}$ is hepatocellular carcinoma (HCC), occurring predominantly in those with cirrhosis ${ }^{3-5}$, but reports have appeared of HCC occurring, although far less commonly, in persons with bridging fibrosis without definite cirrhosis ${ }^{6-10}$. In studies from Asia, the annual incidence of HCC in subjects with hepatitis C-related cirrhosis is reported to be 4-10\%, whereas in European studies, the reported annual incidence is $0.5-5 \%$ in comparable subjects ${ }^{11-13}$. Data on the incidence of HCC in subjects with advanced hepatitis C followed prospectively in the United States (U.S.) are limited. Furthermore, the factors that predict a high likelihood of future HCC in such subjects are not clearly defined.

Data from several previous studies, mostly from Japan, suggested that long-term treatment with interferon-based regimens slowed progression of fibrosis and reduced the occurrence of $\mathrm{HCC}$ in persons with chronic HCV infection ${ }^{14-17}$. To determine whether these results apply also in the U.S., we undertook the Hepatitis C Antiviral Long-Term Treatment against Cirrhosis (HALT-C) Trial. A total of 1,050 persons with chronic hepatitis $\mathrm{C}$ and advanced fibrosis or cirrhosis who were previous nonresponders to antiviral therapy were randomized to receive either a reduced dose of peginterferon or no treatment for 3.5 years ${ }^{18}$. Because 
HCC was one of the planned trial outcomes, the HALT-C trial provided an opportunity to determine in a prospective controlled manner whether long-term peginterferon treatment reduced the incidence of $\mathrm{HCC}$ and to identify risk factors associated with the development of HCC in a U.S. cohort with chronic hepatitis $\mathrm{C}$ and advanced fibrosis or cirrhosis.

\section{PATIENTS AND METHODS}

The design of the HALT-C Trial has been described previously 18,19 . Briefly, patients with detectable HCV RNA at 10 clinical centers had to meet the following criteria for enrollment: failure to have achieved a sustained virologic response (SVR) after previous interferon treatment with or without ribavirin, the presence of advanced hepatic fibrosis on liver biopsy (Ishak fibrosis score $\mathbf{3}$ ), no history of hepatic decompensation or HCC, and the absence of defined exclusion criteria (e.g., liver disease other than hepatitis $\mathrm{C}$, uncontrolled medical or psychiatric conditions, or contraindications to use of interferon or ribavirin).

Patients were treated with pegylated interferon alfa- $2 \mathrm{a}$ ( $180 \mu \mathrm{g}$ weekly) and ribavirin (1-1.2 $\mathrm{g}$ daily) for at least 24 weeks ("Lead-in" phase). Patients who had detectable serum HCV RNA at treatment week 20 (protocol definition of nonresponse) were randomized at week 24 to maintenance therapy (pegylated interferon alfa-2a $90 \mu \mathrm{g}$ weekly) or to no treatment for the next 3.5 years. Patients with undetectable serum HCV RNA at week 20 were considered responders and continued combination therapy for a total of 48 weeks. Patients in the responder group in whom HCV RNA became detectable later during treatment (breakthrough) or after stopping treatment (relapse) were offered enrollment into the randomized trial. After approval of pegylated interferons, the protocol was amended to allow randomization of patients who had failed treatment with pegylated interferon and ribavirin outside this trial (Express patients). Following completion of the 3.5 years of the randomized trial, all patients were invited to continue follow-up without treatment.

All patients were required to have an ultrasound, computed tomography (CT) or magnetic resonance imaging (MRI) with no evidence of hepatic mass lesions suspicious for HCC. Subjects enrolled in the Lead-in phase were required to have serum alpha-fetoprotein (AFP) $<200 \mathrm{ng} / \mathrm{mL}$, while those enrolled as Express patients had to have AFP $<1,000 \mathrm{ng} / \mathrm{mL}$ at the screening visit. Of the 237 Express patients enrolled, only three had AFP $>200 \mathrm{ng} / \mathrm{mL}$ at entry and the highest AFP value was $315 \mathrm{ng} / \mathrm{mL}$.

All patients had a liver biopsy performed prior to enrollment. For Lead-in patients, the baseline liver biopsy was done at least 2 months following the last course of interferon therapy and within 12 months prior to enrollment. For Express patients, a liver biopsy must have been performed within 18 months prior to randomization, or a baseline liver biopsy must have been performed at least 8 weeks after the end of the prior course of peginterferon and ribavirin and within 24 weeks prior to randomization. Liver biopsies were repeated 1.5 and 3.5 years after randomization. All biopsies were reviewed in conference by a panel of 12 hepatic pathologists, who used the Ishak scoring system to grade inflammation (0-18) and to stage fibrosis $(0-6)^{20}$. Liver biopsies performed for the diagnosis of HCC and explant livers of patients who underwent liver transplantation for HCC were also submitted for review by the group of hepatic pathologists.

\section{HCC Surveillance and Diagnostic Criteria}

Patients were seen every 3 months during the 3.5 years of the randomized trial and every 6 months thereafter. Patients who stopped treatment continued to be followed in the study unless consent was withdrawn or a liver transplantation had occurred. A complete blood count, a liver panel, and AFP level were obtained at the local clinical center at each visit. Des-gamma-carboxy prothrombin (DCP) levels at enrollment were tested in batches with an 
enzyme immunoassay (Eisai Company, Tokyo, Japan) in a central laboratory at the University of Michigan; the results were not reported to the investigators at the clinical sites. Lead-in patients underwent an ultrasound examination of the liver 20 weeks and 12 months after enrollment and then every 6-12 months. Express patients underwent ultrasound examinations 6 months after enrollment and then every 6-12 months. Patients with an elevated or rising AFP and those with new lesions on ultrasound were evaluated further with a CT or MRI. Diagnostic liver biopsy and HCC treatment were conducted at the discretion of investigators at each site. All patients underwent an endoscopy at the time of randomization and after 3.5 years (i.e., at the end of the randomized trial). For the current analysis, patients were categorized as not having varices (absent) or as having varices, regardless of their size.

Two definitions of HCC were adopted, one for "definite" HCC and one for "presumed" HCC. Definite HCC was defined by histologic confirmation or a new mass lesion on imaging with AFP levels increasing to $>1,000 \mathrm{ng} / \mathrm{mL}$. Presumed HCC was defined as a new mass lesion on ultrasound in the absence of histology and AFP was $<1,000 \mathrm{ng} / \mathrm{mL}$ in conjunction with one of the following characteristics: a) 2 liver imaging studies showing a mass lesion with characteristics of HCC (vascular enhancement, wash out), b) progressively enlarging lesion on ultrasound leading to death, or c) 1 additional imaging study showing a mass lesion with characteristics of HCC that either increased in size over time or was accompanied by increasing AFP levels. Tumors were staged based on the modified United Network of Organ Sharing (UNOS) TNM system ${ }^{21}$. Early HCC was defined as tumor stage $\mathrm{T} 1$ (single lesion $<2 \mathrm{~cm}$ in diameter) or T2 (single lesion between 2 and $5 \mathrm{~cm}$ or no more than 3 lesions each $<3 \mathrm{~cm}$ in diameter).

All cases of HCC (presumed and definite) were reviewed by an Outcomes Review Panel comprised of rotating panels of three investigators. The outcomes review panel did not include any radiologist and radiographic studies were not reviewed. However, the outcome panel did review serial radiology reports from each HCC case to ascertain that the predefined criteria were met, the date when these criteria were first met, and the tumor staging. In cases where the outcomes review panel was unable to determine if the patient had met criteria for HCC, the investigators were requested to provide additional information including follow-up imaging or histology, and the case re-reviewed. All patients who met criteria for presumed or definite HCC continued to be followed, and results of subsequent imaging or histology (including liver explant and surgically resected specimen) were submitted for review. An earlier report on all trial outcomes (clinical and histological) included randomized patients with definite HCC (incident and prevalent) identified during the first 3.5 years after randomization (up to April 30, 2007) ${ }^{19}$. The current analysis includes all randomized patients in the HALT-C Trial who had a diagnosis of definite or presumed HCC as judged by the Outcomes Review Panel prior to October 15, 2007.

\section{Statistical Analyses}

Statistical analyses were performed at the Data Coordinating Center with SAS release 9.1 (SAS Institute, Cary, NC). Cumulative incidence of HCC was determined by Kaplan Meier analysis and differences compared with the log rank test. Relation of baseline factors to risk of HCC was assessed by $t$-test, chi-square test, or univariate Cox proportional hazards regression. Several multivariate Cox proportional hazards models to estimate the risk of $\mathrm{HCC}$ were tested. Variables with a p value $<0.1$ on univariate analysis and variables reported previously to be associated with $\mathrm{HCC}$ (e.g., gender, race/ethnicity, the presence of cirrhosis, alcohol consumption, and smoking) were entered into a multivariate analysis (model I). Treatment assignment was also included, because the primary goal of the HALT$\mathrm{C}$ Trial was to determine if maintenance therapy with peginterferon would prevent clinical outcomes, including HCC, in patients with chronic hepatitis $\mathrm{C}$ and advanced fibrosis or 
cirrhosis. Alternative multivariate analyses that included AFP and DCP separately and in combination as well as aspartate aminotransferase (AST) and platelet count separately and combined as AST-platelet ratio index (APRI) ${ }^{22}$ were tested. Variables not readily available in clinical practice were deleted from model I to create models with greater clinical utility (models II, III and IV). The cohort was divided into three risk groups based on the resulting individual estimates of model IV. The cumulative incidence of HCC among these groups was determined by Kaplan Meier analysis and compared with the log rank test. A 2-sided significance level of $5 \%$ was used for all analyses.

\section{RESULTS}

A total of 1,050 patients were randomized between January, 2001 and August, 2004. Fortyfive patients were excluded for the following reasons: a) prevalent HCC, defined as HCC diagnosed within 12 months after enrollment ( $\mathrm{n}=5)$; b) patients who had less than 12 months follow-up after enrollment ( $\mathrm{n}=38$ ); and c) patients with a diagnosis of presumed $\mathrm{HCC}$ who were followed for at least 24 months and did not show radiologic or clinical progression of their liver masses $(\mathrm{n}=2)$. The characteristics of the remaining 1,005 patients included in this analysis are shown in Table 1. The mean age of the patients was 50.2 years, $71 \%$ were men, and $72 \%$ were Caucasian. Baseline biopsies showed bridging fibrosis (Ishak 3-4) in 59\% and cirrhosis (Ishak 5-6) in the remaining $41 \%$ of patients. The vast majority of the patients (93\%) had genotype 1 infection.

\section{Incidence of HCC}

During a median follow-up of 4.6 years after randomization (maximum of 6.7 years), 48 (4.8\%) patients met criteria for HCC, 37 (77\%) for definite HCC and 11 (23\%) for presumed HCC (Table 2). Thirty-four (71\%) of the 48 patients with HCC were identified during the randomized phase and the remaining 14 during the extended follow-up period. Thirty six (75\%) patients had early stage (T1/T2) HCC at the time of diagnosis. Twenty-six (54.2\%) patients were eligible for potentially curative treatment: 3 had surgical resection, 17 underwent liver transplantation and 6 had radiofrequency ablation $+/-$ transarterial chemoembolization (TACE). An additional 11 patients had TACE. Thus, in total 37 (77.1\%) patients had tumors diagnosed at an early enough stage that allowed them to receive effective therapies.

Hepatocellular carcinoma developed in a similar proportion of peginterferon-treated patients, $4.5 \%$ (23/495), and controls, $4.9 \%$ (25/510). The estimated annual incidence of $\mathrm{HCC}$ was $1.1 \%$ in peginterferon-treated patients and $1.0 \%$ in controls. The cumulative incidence of $\mathrm{HCC} 3$ and 5 years after randomization was $1.9 \%$ and $5.4 \%$ for peginterferontreated patients and $1.9 \%$ and $5.0 \%$ for controls, respectively ( $\mathrm{p}=0.78$ ) (Figure 1A). The incidence of $\mathrm{HCC}$ in the peginterferon-treated and control groups was similar regardless of the inclusion or exclusion of cases of presumed HCC.

HCC was diagnosed in a higher percent of patients with cirrhosis, 6.1\% (25/408), than in those with bridging fibrosis, 3.9\% (23/597). The estimated annual incidence of HCC was $0.8 \%$ among patients with bridging fibrosis and $1.4 \%$ among those with cirrhosis. The cumulative incidence of HCC 3 and 5 years after randomization was $2.6 \%$ and $7.0 \%$ for patients with cirrhosis and $1.4 \%$ and $4.1 \%$ for those with bridging fibrosis, respectively $(\mathrm{p}=0.08)$ (Figure 1B).

\section{HCC in patients without cirrhosis at enrollment}

Of the 23 patients with $\mathrm{HCC}$ and an Ishak fibrosis score of 3 or 4 at enrollment, 13 advanced to a score of 5-6, seven remained with a score of $3-4$, and two had a score of 2 on 
subsequent biopsies, liver explants or surgically resected specimen; two patients did not have repeat biopsies (Table 3). Thus, 17\% (8/48) of the patients in whom HCC developed did not have cirrhosis on at least two biopsies more than 2 years apart. HCC was diagnosed after a median of 46.5 months (range 26-72) from enrollment in these eight patients. At enrollment, six of these eight patients had platelet counts $>150,000 / \mathrm{mm}^{3}$, and none had esophageal varices; however, at the time of the diagnosis of HCC, only one patient had a platelet count $>150,000 / \mathrm{mm}^{3}$ (Table 4 ).

\section{Risk factors for HCC}

Baseline clinical and laboratory characteristics of the patients with and without $\mathrm{HCC}$ are shown in Table 1. Based on univariate analysis, older age, lower BMI, lower white cell and platelet counts, a lower albumin level, higher levels of alkaline phosphatase, AST, alanine aminotransferase (ALT), AFP, and DCP, and the presence of esophageal varices were significantly associated with HCC (each $\mathrm{p}<0.05)$. Black race, higher international normalized ratio of prothrombin time (INR), and histological evidence of cirrhosis showed a trend toward significance $(\mathrm{p}<0.1)$, while gender, diabetes, alcohol consumption, smoking, treatment assignment, HCV genotype, and bilirubin were not significantly associated with HCC.

\section{Models to predict HCC incidence}

Several Cox proportional hazards models were developed to predict the risk of HCC (Table 5). The initial model (Model I), which included significant variables from our univariate analysis or from previously published analyses, was modified to eliminate variables that were not significant on multivariate analysis. Three simplified models (Models II-IV) are shown, because they include variables that are available in most patients with chronic hepatitis C. The final model (Model IV) included age in years (continuous), black race (black=1, non-black=0), alkaline phosphatase in $\mathrm{U} / \mathrm{L}$ (continuous), the presence of esophageal varices (present $=1$; absent $=0$ ), smoking (ever smoked $=1$, never smoked $=0$ ), and platelet count $\times 1,000 / \mathrm{mm}^{3}$ (continuous). The regression formula for model IV is as follows: age $* 0.049+$ black race* $0.712+$ alkaline phosphatase $* 0.006+$ esophageal varices $* 0.777+$ ever smoked*0.749 + platelets*-0.011. A score was calculated for each subject included in this study, and cases were ranked in order of their calculated scores in this model. Three cut points [0 to $\log _{10}(1.50), \log _{10}(1.50)$ to $\log _{10}(3.25)$, and $>\log _{10}$ (3.25)] were selected to reflect low, intermediate, and high risk, as distinguished by 5 -year cumulative incidence of $\mathrm{HCC}$ of $<1 \%, 1-5 \%$, and $>5 \%$. The cumulative incidence of HCC 3 and 5 years after randomization was $0 \%$ and $0.4 \%$ for patients in the low risk group; $1.5 \%$ and $4.2 \%$ for patients in the intermediate risk group; and $6.1 \%$ and $17.8 \%$ for patients in the high risk group, respectively (Figure 2).

Low platelet count and presence of esophageal varices were highly significant in the models tested. The impact of esophageal varices and platelet count on the incidence of HCC is shown in Figures 3A and 3B. The cumulative incidence of HCC 3 and 5 years after randomization was $5.3 \%$ and $13.1 \%, 2.4 \%$ and $5.7 \%$, and $0.6 \%$ and $2.6 \%$ for patients with baseline platelet count $<100,100-149$, and $>150 \times 1000 / \mathrm{mm}^{3}$, respectively. The estimated annual incidence of $\mathrm{HCC}$ for patients in these three strata of platelet counts was $2.6 \%, 1.1 \%$, and $0.5 \%$, respectively.

\section{DISCUSSION}

The major objective of the HALT-C Trial was to determine whether long-term treatment with peginterferon would reduce progression of hepatitis $\mathrm{C}$, including the development of HCC. Support for the possibility that maintenance therapy might inhibit disease progression 
had come from a 2-year study of interferon maintenance therapy in a U.S. population ${ }^{23}$. Additionally, several early reports suggested that interferon therapy reduced the development of HCC in Japanese and Italian patients with chronic hepatitis $C^{14-17}$. Following initiation of the HALT-C Trial in 2000, numerous additional studies were published that addressed the issue of antiviral treatment and development of HCC, leading Craxi and Camma to perform a meta-analysis in 2005 of the then-existing studies ${ }^{24}$. The analysis included 20 trials, most of which were not randomized studies and 19 of which showed (13 significantly) that antiviral therapy reduced the rate of development of HCC. The validity of the meta-analysis, however, was limited by the marked heterogeneity among the studies. The authors concluded that, although interferon treatment appeared to have a beneficial impact on reducing the development of HCC, the effect was slight and was most evident among the relatively few patients with cirrhosis who achieved an SVR. More recent studies from Japan and Taiwan, however, have continued to support a positive impact of antiviral therapy on the occurrence of $\mathrm{HCC}^{25-28}$, but patients in these trials were not randomized and, again, the benefit was observed mainly in patients who had achieved an SVR.

In the present study, we found no significant difference in the incidence of HCC between patients randomized to receive peginterferon maintenance therapy $(23 / 495 ; 4.7 \%)$ and those randomized to no treatment $(25 / 510 ; 4.9 \%)$. The cumulative incidence of HCC 5 years after randomization in the two cohorts was almost identical (treated: 5.4\% and controls: 5.0\%). These data, collected prospectively from a large number of subjects followed closely for a median of 4.6 years, suggest strongly that maintenance therapy with peginterferon, $90 \mu \mathrm{g} /$ week, does not reduce the incidence of HCC in patients with chronic hepatitis $\mathrm{C}$ and advanced fibrosis or cirrhosis.

Because treatment had no effect on the rate of development of HCC in this trial, data from the two cohorts (treated and untreated) could be combined to provide information on the annual incidence of HCC among patients with advanced HCV-related liver disease in the U.S. followed prospectively. Thus, for the combined cohort, the 3-year incidence of HCC from study entry was $1.9 \%$, increasing to $5.9 \%$ at 5 years, yielding an annual incidence of $\mathrm{HCC}$ of $1.1 \%$. This figure is consistent with, but at the lower range of, previous estimates of the annual incidence of HCC both in the United States ${ }^{29}$, now increasing ${ }^{30}$, and in Europe $3,4,12$ but clearly lower than the rates reported among HCV-infected persons in Japan ${ }^{31-33}$.

The most likely explanation for the disparity between this trial and others in the efficacy of interferon-based therapy in reducing the incidence of $\mathrm{HCC}$ is the difference in study design between the HALT-C Trial and many of the previous studies. The HALT-C Trial was a large, well powered, prospective, randomized, multicenter trial, with clear, predefined criteria for the diagnosis of HCC. Many prior studies of interferon treatment were relatively small, nonrandomized, and/or retrospective, with all the potential pitfalls of such observations. Furthermore, in several previous reports, the decreased incidence of HCC was observed mainly in patients who achieved an SVR, subjects who were excluded from the HALT-C Trial. Potentially, the HALT-C Trial might have demonstrated efficacy of antiviral therapy in preventing HCC had the maintenance treatment consisted of full-dose peginterferon and ribavirin instead of half-dose peginterferon only. However, it is unlikely that patients with advanced fibrosis or cirrhosis could tolerate full-dose combination therapy for 3.5 years; only $59 \%$ of patients in the HALT-C Trial randomized to receive half-dose peginterferon therapy were able to tolerate this lower dose for the entire 3.5 years. Finally, the lower incidence of HCC observed in the HALT-C Trial compared to previous studies could be related to differences in radiological and histological diagnostic criteria for HCC. In the current study, cases of HCC identified within 12 months of enrollment were excluded 
as the tumors may have been present prior to entry into the trial. Although 23\% (11/48) of the HCC cases in our trial were categorized as presumed, rather than definite, HCC, almost all of these cases fulfilled currently accepted diagnostic criteria for $\mathrm{HCC}^{34-36}$. Indeed, the diagnostic criteria utilized in this study were very stringent, and the outcome was the same whether we included presumed cases or not.

The rate of HCC was higher in those whose baseline liver biopsy displayed cirrhosis than in those with bridging fibrosis ( 6.1 percent versus 3.9 percent; $p=0.08$ ). While HCC has been reported rarely in patients with chronic hepatitis $\mathrm{C}$ in the absence of cirrhosis, the high frequency of HCC among subjects without cirrhosis in the present study was unexpected ${ }^{6-9,37}$. One possible explanation is under-staging of the baseline liver biopsy resulting from sampling error; however, eight of the 23 patients with HCC who had no cirrhosis at enrollment also had no cirrhosis on follow-up liver biopsy (all 8 patients) or on explant (1 patient). Alternatively, hepatic fibrosis may have progressed between the time of the last study biopsy and the subsequent diagnosis of HCC as the interval between the last biopsy with no cirrhosis and HCC diagnosis varied from 0-34 months (median 16). Whatever the explanation for our observation, the development of HCC in persons with noncirrhotic fibrosis raises the question of whether such patients should undergo HCC surveillance, as is recommended for persons with established cirrhosis ${ }^{33}$.

In seeking to identify features that might predict the future development of HCC, we undertook an extensive analysis of baseline demographic characteristics, metabolic and viral factors, laboratory values (including HCC biomarkers), disease severity, histologic findings, markers of portal hypertension, treatment assignment, physical activity, and history of alcohol use, smoking, and hormone use in women. On univariate analysis, treatment group assignment was not associated with risk of HCC, and we could not confirm associations reported by others between diabetes or alcohol use and the development of HCC ${ }^{38-43}$. In the current study, subjects with HCC had a lower BMI, not only at enrollment, but also, based upon historical information, at ages 20 and 40, than subjects in whom HCC did not develop. Prior reports of an association between obesity and HCC may have included patients with non-alcoholic fatty liver disease ${ }^{44-46}$. In this study, a strong association was observed between the risk of HCC and a low platelet count, a high AST level, and the presence of esophageal varices. This finding is consistent with an association in several studies from Asia between a low platelet count and the development of $\mathrm{HCC}^{47,48}$ and an association in a study from Italy between the presence of esophageal varices and HCC ${ }^{49}$.

Numerous efforts have been made to develop predictive models for the development of HCC in persons with advanced chronic liver disease ${ }^{50-53}$. In multivariate analyses, these investigators have identified varying factors, including age, gender, platelet count, prothrombin time, albumin level, and AFP, as predictive variables. In the current study, we found that gender, cirrhosis, and AFP were not significant in all models tested, while DCP was. Smoking was not a significant factor on univariate analysis but was significant in several regression models tested and showed a trend in our final model. Several simplified models that included factors easily accessible in routine clinical settings were developed to aid in predicting the risk of HCC among patients with hepatitis $\mathrm{C}$ and advanced fibrosis or cirrhosis. These models may be useful for selecting high-risk patients with bridging fibrosis and cirrhosis for HCC surveillance.

\section{CONCLUSIONS}

In the current analysis of hepatitis $\mathrm{C}$ patients with advanced fibrosis enrolled in the HALT-C Trial, 3.5 years of maintenance therapy with peginterferon did not reduce the incidence of HCC. The $1 \%$ annual incidence of HCC in this U.S. cohort was lower than those reported in 
studies of similar patients in Japan and Europe. Modeling based upon clinical and laboratory features can identify patients at higher risk who might be candidates for more intense HCC surveillance. Additional studies are required to confirm the occurrence of $\mathrm{HCC}$ among patients with bridging fibrosis but no cirrhosis and to determine whether such patients should undergo HCC surveillance.

\section{Acknowledgments}

This study was supported by the National Institute of Diabetes \& Digestive \& Kidney Diseases (contract numbers are listed below). Additional support was provided by the National Institute of Allergy and Infectious Diseases (NIAID), the National Cancer Institute, the National Center for Minority Health and Health Disparities and by General Clinical Research Center grants from the National Center for Research Resources, National Institutes of Health (grant numbers are listed below). Additional funding to conduct this study was supplied by Hoffman-La Roche, Inc., through a Cooperative Research and Development Agreement (CRADA) with the National Institutes of Health.

In addition to the authors of this manuscript, the following individuals were instrumental in the planning, conduct and/or care of patients enrolled in this study at each of the participating institutions as follows:

University of Massachusetts Medical Center, Worcester, MA: (Contract N01-DK-9-2326) Gyongyi Szabo, MD, Barbara F. Banner, MD, Maureen Cormier, RN, Donna Giansiracusa, RN

University of Connecticut Health Center, Farmington, CT: (Grant M01RR-06192) Michelle Kelley, RN, ANP

Saint Louis University School of Medicine, St Louis, MO: (Contract N01-DK-9-2324) Bruce Bacon, MD, Brent Neuschwander-Tetri, MD, Debra King, RN

Massachusetts General Hospital, Boston, MA: (Contract N01-DK-9-2319, Grant M01RR-01066), Raymond T. Chung, MD, Andrea E. Reid, MD, Atul K. Bhan, MD, Wallis A. Molchen

University of Colorado School of Medicine, Denver, CO: (Contract N01-DK-9-2327, Grant M01RR-00051) S. Russell Nash, MD, Jennifer DeSanto, RN, Carol McKinley, RN

University of California - Irvine, Irvine, CA: (Contract N01-DK-9-2320, Grant M01RR-00827) John C. Hoefs, MD, John R. Craig, MD, M. Mazen Jamal, MD, MPH, Muhammad Sheikh, MD, Choon Park, RN

University of Texas Southwestern Medical Center, Dallas, TX: (Contract N01-DK-9-2321, Grant M01RR-00633) Thomas E. Rogers, MD, Janel Shelton, Nicole Crowder, LVN, Rivka Elbein, RN, BSN

University of Southern California, Los Angeles, CA: (Contract N01-DK-9-2325, Grant M01RR-00043) Sugantha Govindarajan, MD, Carol B. Jones, RN, Susan L. Milstein, RN

University of Michigan Medical Center, Ann Arbor, MI: (Contract N01-DK-9-2323, Grant M01RR-00042) Robert J. Fontana, MD, Joel K. Greenson, MD, Pamela A. Richtmyer, LPN, CCRC, R. Tess Bonham, BS

Virginia Commonwealth University Health System, Richmond, VA: (Contract N01-DK-9-2322, Grant M01RR-00065) Mitchell L. Shiffman, MD, Melissa J. Contos, MD, A. Scott Mills, MD, Charlotte Hofmann, RN, Paula Smith, RN

Liver Diseases Branch, National Institute of Diabetes and Digestive and Kidney Diseases, National Institutes of Health, Bethesda, MD: T. Jake Liang, MD, David Kleiner, MD, PhD, Yoon Park, RN, Elenita Rivera, RN, Vanessa Haynes-Williams, RN

National Institute of Diabetes and Digestive and Kidney Diseases, Division of Digestive Diseases and Nutrition, Bethesda, MD: James E. Everhart, MD, MPH, Elizabeth C. Wright, PhD, Jay H. Hoofnagle, MD

University of Washington, Seattle, WA: (Contract N01-DK-9-2318), David R. Gretch, MD, PhD, Minjun Chung Apodaca, BS, ASCP, Rohit Shankar, BC, ASCP

New England Research Institutes, Watertown, MA: (Contract N01-DK-9-2328) Kristin K. Snow, MSc, ScD, Anne M. Stoddard, ScD, Linda Massey

Armed Forces Institute of Pathology, Washington, DC: Fanny Monge, Michelle Parks 
Data and Safety Monitoring Board Members: (Chair) Gary L. Davis, MD, Guadalupe Garcia-Tsao, MD, Michael Kutner, PhD, Stanley M. Lemon, MD, Robert P. Perrillo, MD

\section{References}

1. Chen SL, Morgan TR. The natural history of hepatitis C virus (HCV) infection. Int J Med Sci. 2006; 3(2):47-52. [PubMed: 16614742]

2. Thomas DL, Seeff LB. Natural history of hepatitis C. Clin Liver Dis. 2005; 9(3):383-98. vi. [PubMed: 16023972]

3. Benvegnu L, Gios M, Boccato S, Alberti A. Natural history of compensated viral cirrhosis: a prospective study on the incidence and hierarchy of major complications. Gut. 2004; 53(5):744-9. [PubMed: 15082595]

4. Fattovich G, Giustina G, Degos F, et al. Morbidity and mortality in compensated cirrhosis type C: a retrospective follow-up study of 384 patients. Gastroenterology. 1997; 112(2):463-72. [PubMed: 9024300]

5. Simonetti RG, Camma C, Fiorello F, et al. Hepatitis C virus infection as a risk factor for hepatocellular carcinoma in patients with cirrhosis. A case-control study. Ann Intern Med. 1992; 116(2):97-102. [PubMed: 1309286]

6. Bege T, Le Treut YP, Hardwigsen J, et al. Prognostic factors after resection for hepatocellular carcinoma in nonfibrotic or moderately fibrotic liver. A 116-case European series. J Gastrointest Surg. 2007; 11(5):619-25. [PubMed: 17468920]

7. Lawson A, Hagan S, Rye K, et al. The natural history of hepatitis $\mathrm{C}$ with severe hepatic fibrosis. J Hepatol. 2007; 47(1):37-45. [PubMed: 17400322]

8. Bralet MP, Regimbeau JM, Pineau P, et al. Hepatocellular carcinoma occurring in nonfibrotic liver: epidemiologic and histopathologic analysis of 80 French cases. Hepatology. 2000; 32(2):200-4. [PubMed: 10915724]

9. Le Treut YP, Pons J, Hardwigsen J, et al. Hepatocellular carcinoma in a non-cirrhotic liver. Presentation of series of 77 operated patients. Chirurgie. 1999; 124(5):485-93. [PubMed: 10615775]

10. Nzeako UC, Goodman ZD, Ishak KG. Hepatocellular carcinoma in cirrhotic and noncirrhotic livers. A clinico-histopathologic study of 804 North American patients. Am J Clin Pathol. 1996; 105(1):65-75. [PubMed: 8561091]

11. El-Serag HB, Rudolph KL. Hepatocellular carcinoma: epidemiology and molecular carcinogenesis. Gastroenterology. 2007; 132(7):2557-76. [PubMed: 17570226]

12. Seeff LB, Hoofnagle JH. Epidemiology of hepatocellular carcinoma in areas of low hepatitis B and hepatitis C endemicity. Oncogene. 2006; 25(27):3771-7. [PubMed: 16799618]

13. Parkin, D. Cancer incidence in five countries. Lyon: IARC scientific publications; 2002.

14. Yoshida H, Shiratori Y, Moriyama M, et al. Interferon therapy reduces the risk for hepatocellular carcinoma: national surveillance program of cirrhotic and noncirrhotic patients with chronic hepatitis C in Japan. IHIT Study Group. Inhibition of Hepatocarcinogenesis by Interferon Therapy. Ann Intern Med. 1999; 131(3):174-81. [PubMed: 10428733]

15. Imai Y, Kawata $S$, Tamura $S$, et al. Relation of interferon therapy and hepatocellular carcinoma in patients with chronic hepatitis C. Osaka Hepatocellular Carcinoma Prevention Study Group. Ann Intern Med. 1998; 129(2):94-9. [PubMed: 9669992]

16. Mazzella G, Accogli E, Sottili S, et al. Alpha interferon treatment may prevent hepatocellular carcinoma in HCV-related liver cirrhosis. J Hepatol. 1996; 24(2):141-7. [PubMed: 8907566]

17. Nishiguchi S, Kuroki T, Nakatani S, et al. Randomised trial of effects of interferon-alpha on incidence of hepatocellular carcinoma in chronic active hepatitis C with cirrhosis. Lancet. 1995; 346(8982):1051-5. [PubMed: 7564784]

18. Lee WM, Dienstag JL, Lindsay KL, et al. Evolution of the HALT-C Trial: pegylated interferon as maintenance therapy for chronic hepatitis $\mathrm{C}$ in previous interferon nonresponders. Control Clin Trials. 2004; 25(5):472-92. [PubMed: 15465617] 
19. Di Bisceglie AM, Shiffman ML, Everson GT, et al. Prolonged therapy of advanced chronic hepatitis $\mathrm{C}$ with peginterferon: the Hepatitis $\mathrm{C}$ Antiviral Long-Term Treatment against Cirrhosis (HALT-C) Trial. New Engl J Med. in press.

20. Ishak K, Baptista A, Bianchi L, et al. Histological grading and staging of chronic hepatitis. J Hepatol. 1995; 22(6):696-9. [PubMed: 7560864]

21. Marsh JW, Dvorchik I, Bonham CA, Iwatsuki S. Is the pathologic TNM staging system for patients with hepatoma predictive of outcome? Cancer. 2000; 88(3):538-43. [PubMed: 10649244]

22. Wai CT, Greenson JK, Fontana RJ, et al. A simple noninvasive index can predict both significant fibrosis and cirrhosis in patients with chronic hepatitis C. Hepatology. 2003; 38(2):518-26. [PubMed: 12883497]

23. Shiffman ML, Hofmann CM, Contos MJ, et al. A randomized, controlled trial of maintenance interferon therapy for patients with chronic hepatitis $\mathrm{C}$ virus and persistent viremia. Gastroenterology. 1999; 117(5):1164-72. [PubMed: 10535880]

24. Craxi A, Camma C. Prevention of hepatocellular carcinoma. Clin Liver Dis. 2005; 9(2):329-46. viii. [PubMed: 15831277]

25. Arase Y, Ikeda K, Suzuki F, et al. Prolonged-interferon therapy reduces hepatocarcinogenesis in aged-patients with chronic hepatitis C. J Med Virol. 2007; 79(8):1095-102. [PubMed: 17597485]

26. Yu ML, Lin SM, Chuang WL, et al. A sustained virological response to interferon or interferon/ ribavirin reduces hepatocellular carcinoma and improves survival in chronic hepatitis C: a nationwide, multicentre study in Taiwan. Antivir Ther. 2006; 11(8):985-94. [PubMed: 17302368]

27. Shiratori Y, Ito Y, Yokosuka O, et al. Antiviral therapy for cirrhotic hepatitis C: association with reduced hepatocellular carcinoma development and improved survival. Ann Intern Med. 2005; 142(2):105-14. [PubMed: 15657158]

28. Saito Y, Saito H, Tada S, et al. Effect of long-term interferon therapy for refractory chronic hepatitis c: preventive effect on hepatocarcinogenesis. Hepatogastroenterology. 2005; 52(65): 1491-6. [PubMed: 16201104]

29. El-Serag HB. Hepatocellular carcinoma and hepatitis C in the United States. Hepatology. 2002; 36(5 Suppl 1):S74-83. [PubMed: 12407579]

30. Davila JA, Morgan RO, Shaib Y, McGlynn KA, El-Serag HB. Hepatitis C infection and the increasing incidence of hepatocellular carcinoma: a population-based study. Gastroenterology. 2004; 127(5):1372-80. [PubMed: 15521006]

31. Kiyosawa K, Umemura T, Ichijo T, et al. Hepatocellular carcinoma: recent trends in Japan. Gastroenterology. 2004; 127(5 Suppl 1):S17-26. [PubMed: 15508082]

32. Raza SA, Clifford GM, Franceschi S. Worldwide variation in the relative importance of hepatitis B and hepatitis C viruses in hepatocellular carcinoma: a systematic review. Br J Cancer. 2007; 96(7): 1127-34. [PubMed: 17406349]

33. Imazeki F, Yokosuka O, Fukai K, et al. Lower incidence of hepatic failure than hepatocellular carcinoma in Japanese patients with chronic hepatitis C. Liver Int. 2005; 25(4):772-8. [PubMed: 15998428]

34. Bruix J, Sherman M. Management of hepatocellular carcinoma. Hepatology. 2005; 42(5):1208-36. [PubMed: 16250051]

35. Bruix J, Sherman M, Llovet JM, et al. Clinical management of hepatocellular carcinoma. Conclusions of the Barcelona-2000 EASL conference. European Association for the Study of the Liver. J Hepatol. 2001; 35(3):421-30. [PubMed: 11592607]

36. Befeler AS, Hayashi PH, Di Bisceglie AM. Liver transplantation for hepatocellular carcinoma. Gastroenterology. 2005; 128(6):1752-64. [PubMed: 15887162]

37. Veldt BJ, Heathcote EJ, Wedemeyer H, et al. Sustained virologic response and clinical outcomes in patients with chronic hepatitis C and advanced fibrosis. Ann Intern Med. 2007; 147(10):677-84. [PubMed: 18025443]

38. Lai MS, Hsieh MS, Chiu YH, Chen TH. Type 2 diabetes and hepatocellular carcinoma: A cohort study in high prevalence area of hepatitis virus infection. Hepatology. 2006; 43(6):1295-302. [PubMed: 16729295] 
39. Davila JA, Morgan RO, Shaib Y, McGlynn KA, El-Serag HB. Diabetes increases the risk of hepatocellular carcinoma in the United States: a population based case control study. Gut. 2005; 54(4):533-9. [PubMed: 15753540]

40. Fujita Y, Shibata A, Ogimoto I, et al. The effect of interaction between hepatitis C virus and cigarette smoking on the risk of hepatocellular carcinoma. Br J Cancer. 2006; 94(5):737-9. [PubMed: 16465190]

41. Franceschi S, Montella M, Polesel J, et al. Hepatitis viruses, alcohol, and tobacco in the etiology of hepatocellular carcinoma in Italy. Cancer Epidemiol Biomarkers Prev. 2006; 15(4):683-9. [PubMed: 16614109]

42. Yu MC, Yuan JM. Environmental factors and risk for hepatocellular carcinoma. Gastroenterology. 2004; 127(5 Suppl 1):S72-8. [PubMed: 15508106]

43. Said A, Williams J, Holden J, Remington P, Musat A, Lucey MR. The prevalence of alcoholinduced liver disease and hepatitis $\mathrm{C}$ and their interaction in a tertiary care setting. Clin Gastroenterol Hepatol. 2004; 2(10):928-34. [PubMed: 15476157]

44. Pekow JR, Bhan AK, Zheng H, Chung RT. Hepatic steatosis is associated with increased frequency of hepatocellular carcinoma in patients with hepatitis C-related cirrhosis. Cancer. 2007; 109(12):2490-6. [PubMed: 17487861]

45. Kumar D, Farrell GC, Kench J, George J. Hepatic steatosis and the risk of hepatocellular carcinoma in chronic hepatitis C. J Gastroenterol Hepatol. 2005; 20(9):1395-400. [PubMed: 16105127]

46. Marrero JA, Fontana RJ, Su GL, Conjeevaram HS, Emick DM, Lok AS. NAFLD may be a common underlying liver disease in patients with hepatocellular carcinoma in the United States. Hepatology. 2002; 36(6):1349-54. [PubMed: 12447858]

47. Lu SN, Wang JH, Liu SL, et al. Thrombocytopenia as a surrogate for cirrhosis and a marker for the identification of patients at high-risk for hepatocellular carcinoma. Cancer. 2006; 107(9):2212-22. [PubMed: 17019738]

48. Kubo S, Tanaka H, Shuto T, et al. Correlation between low platelet count and multicentricity of hepatocellular carcinoma in patients with chronic hepatitis C. Hepatol Res. 2004; 30(4):221-5. [PubMed: 15589130]

49. Giannini EG, Risso D, Testa R, et al. Prevalence and prognostic significance of the presence of esophageal varices in patients with hepatocellular carcinoma. Clin Gastroenterol Hepatol. 2006; 4(11):1378-84. [PubMed: 17059899]

50. Bonis PA, Tong MJ, Blatt LM, Conrad A, Griffith JL. A predictive model for the development of hepatocellular carcinoma, liver failure, or liver transplantation for patients presenting to clinic with chronic hepatitis C. Am J Gastroenterol. 1999; 94(6):1605-12. [PubMed: 10364032]

51. Ganne-Carrie N, Chastang C, Chapel F, et al. Predictive score for the development of hepatocellular carcinoma and additional value of liver large cell dysplasia in Western patients with cirrhosis. Hepatology. 1996; 23(5):1112-8. [PubMed: 8621142]

52. Velazquez RF, Rodriguez M, Navascues CA, et al. Prospective analysis of risk factors for hepatocellular carcinoma in patients with liver cirrhosis. Hepatology. 2003; 37(3):520-7. [PubMed: 12601348]

53. Rodriguez-Diaz JL, Rosas-Camargo V, Vega-Vega O, et al. Clinical and pathological factors associated with the development of hepatocellular carcinoma in patients with hepatitis virusrelated cirrhosis: a long-term follow-up study. Clin Oncol (R Coll Radiol). 2007; 19(3):197-203. [PubMed: 17359907]

54. Lok AS, Ghany MG, Goodman ZD, et al. Predicting cirrhosis in patients with hepatitis C based on standard laboratory tests: results of the HALT-C cohort. Hepatology. 2005; 42(2):282-92. [PubMed: 15986415] 
Figure 1A

\section{Time to HCC Diagnosis}

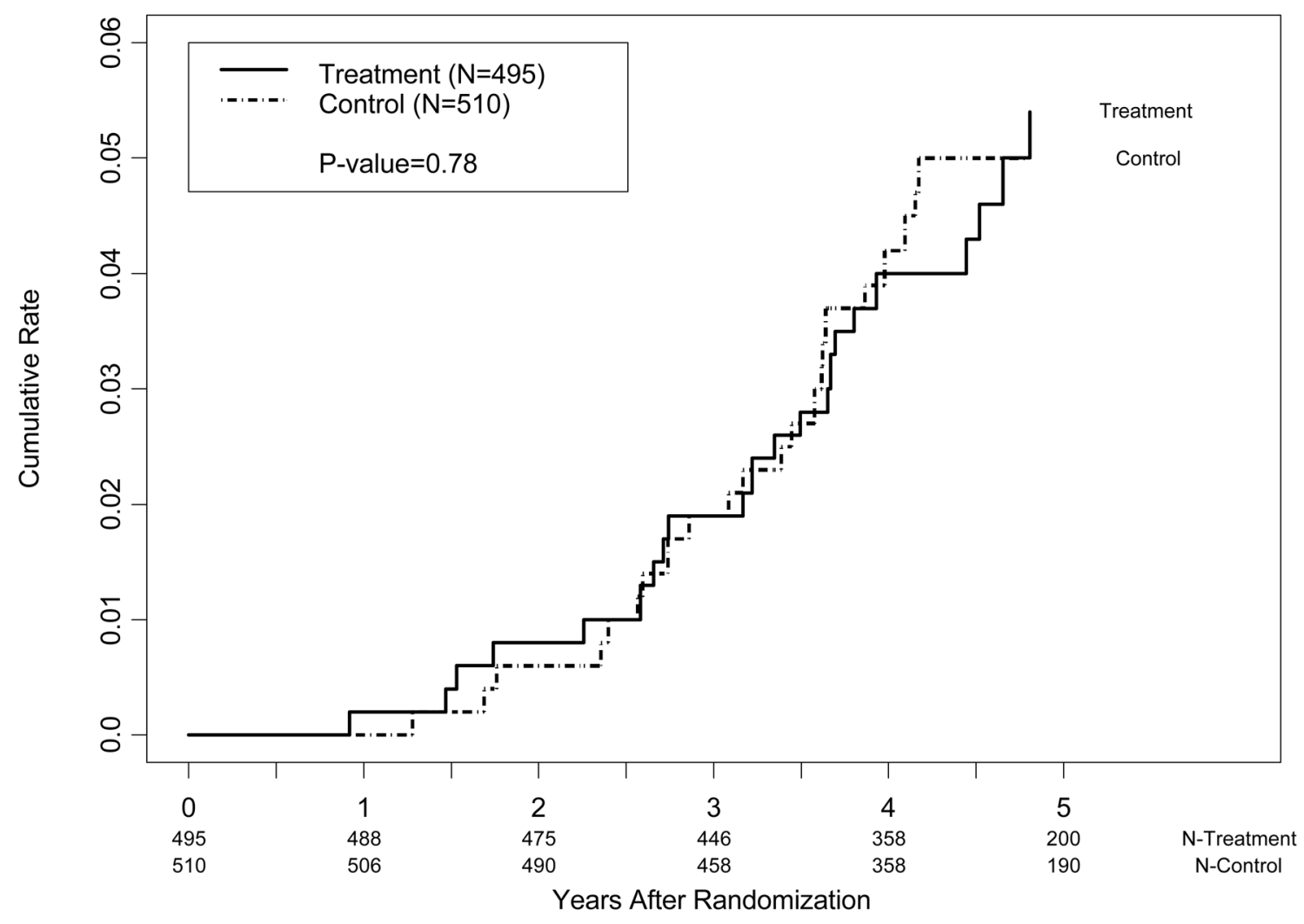

Gastroenterology. Author manuscript; available in PMC 2013 August 22. 


\section{Figure 1B}

\section{Time to HCC Diagnosis}

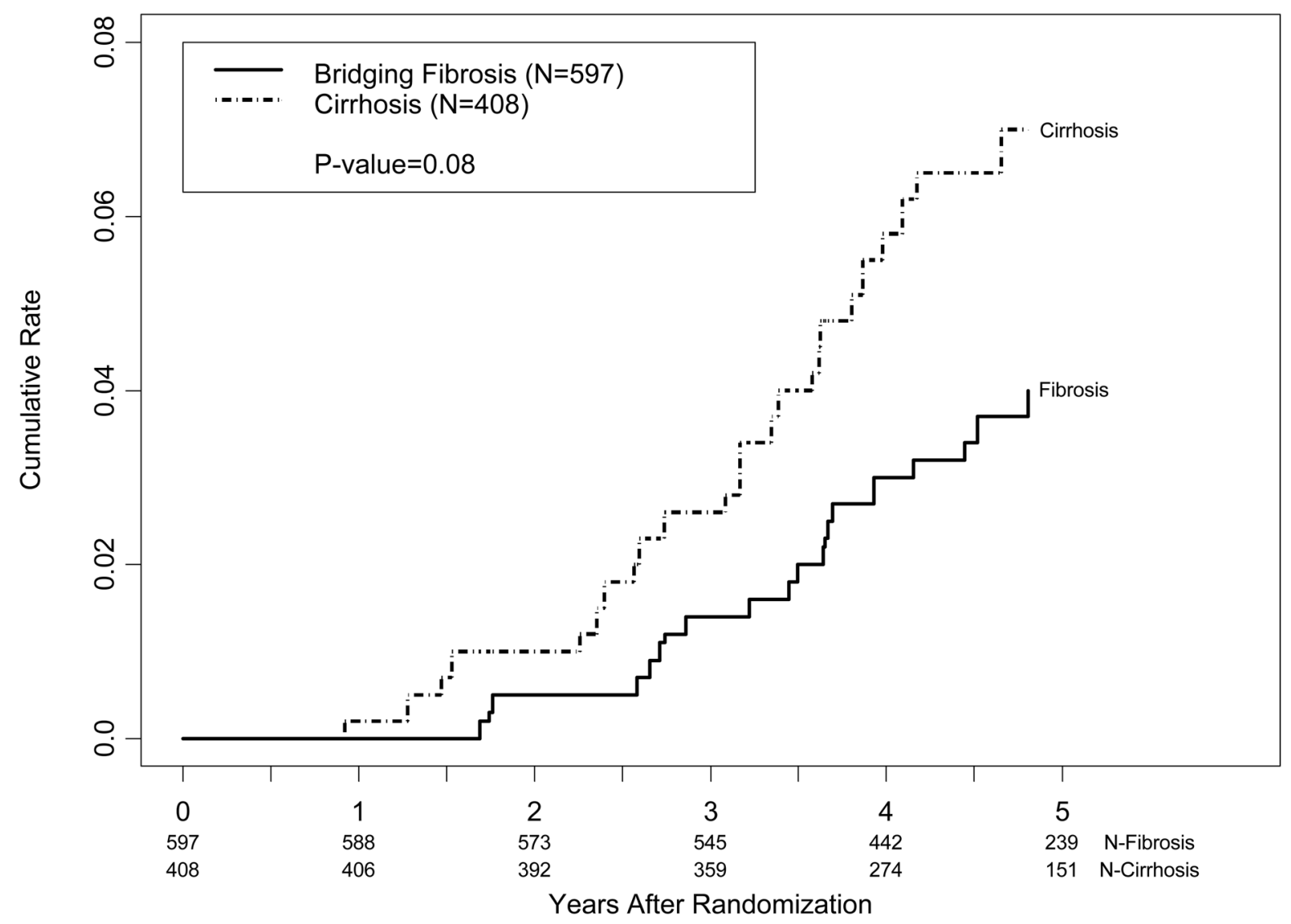

Figure 1.

Kaplan-Meier estimates of cumulative incidence of HCC (A) among patients randomized to maintenance peginterferon treatment or control and (B) among patients with bridging fibrosis (Ishak 3-4) vs. cirrhosis (Ishak 5-6) on baseline biopsy. Cases diagnosed within 12 months of enrollment were presumed to have been present at the time of enrollment and were excluded. One patient in the treatment group met criteria for HCC 11 months after randomization. This patient relapsed after 48 weeks of Lead-in treatment and had been in the study for 16 months at the time of randomization. 


\section{Cumulative incidence of $\mathrm{HCC}$}

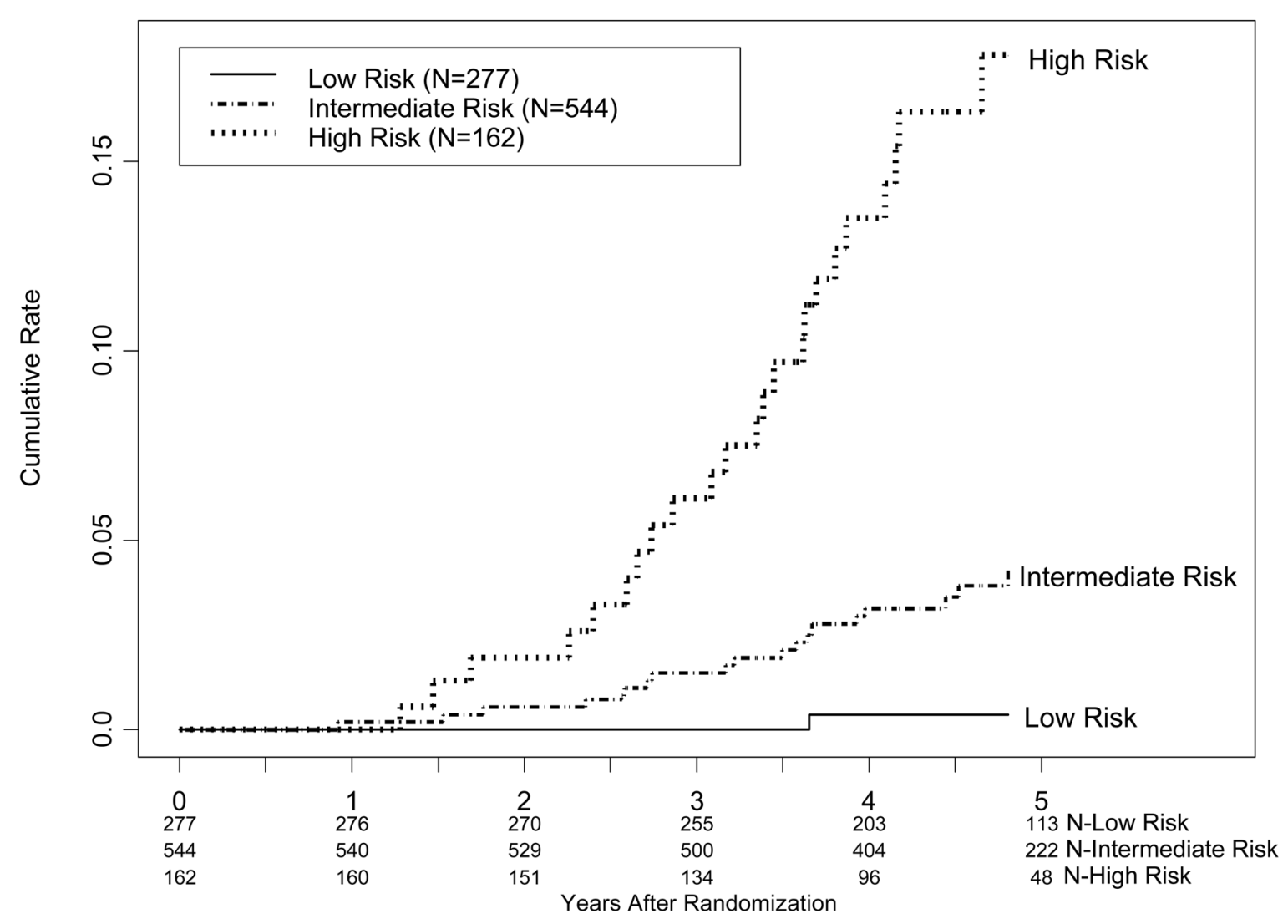

Figure 2.

Kaplan-Meier estimates of cumulative incidence of $\mathrm{HCC}$ among patients predicted to have low, intermediate, and high risk of HCC according to regression Model IV. 
Figure 3A

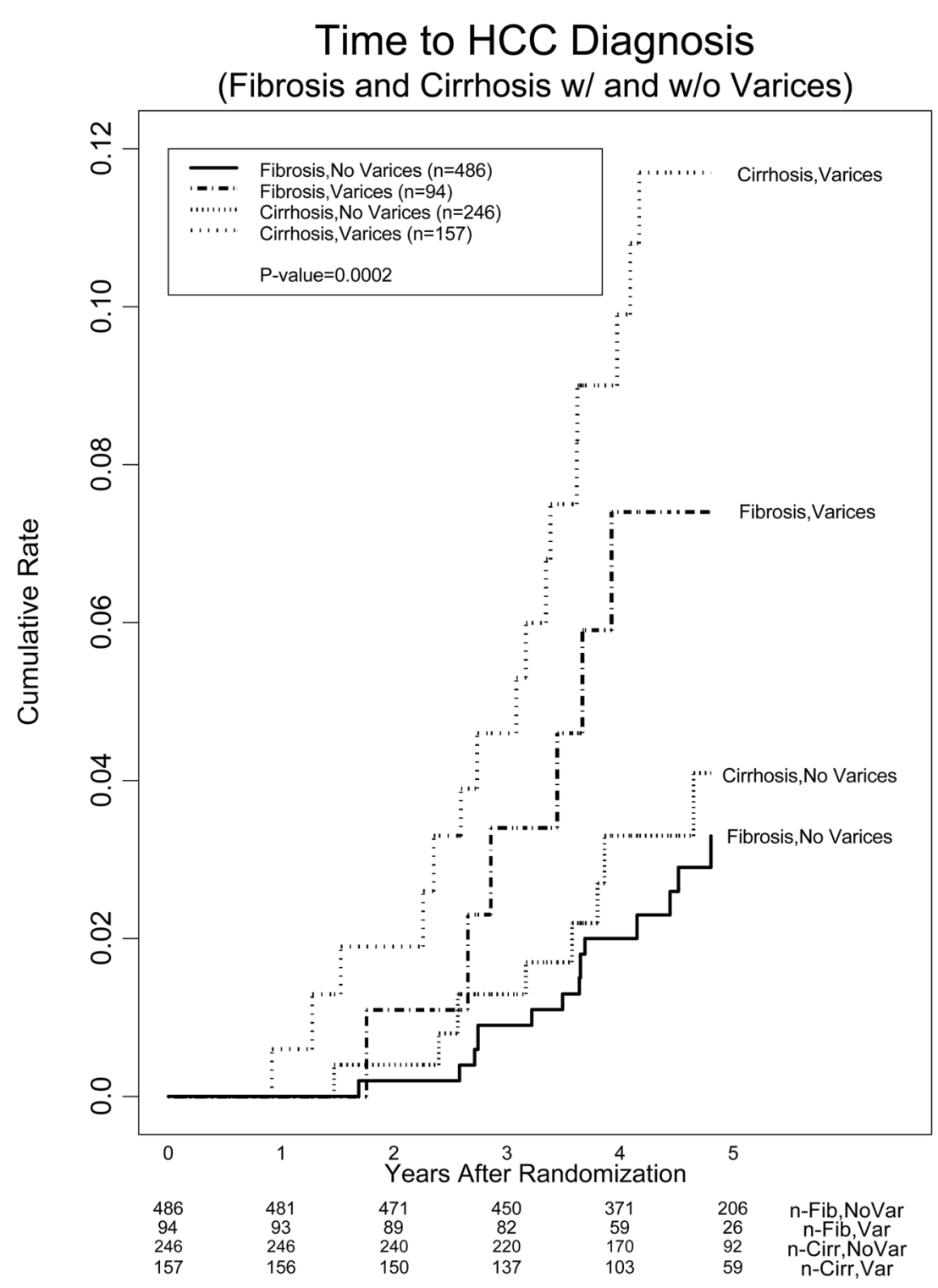


Figure 3B

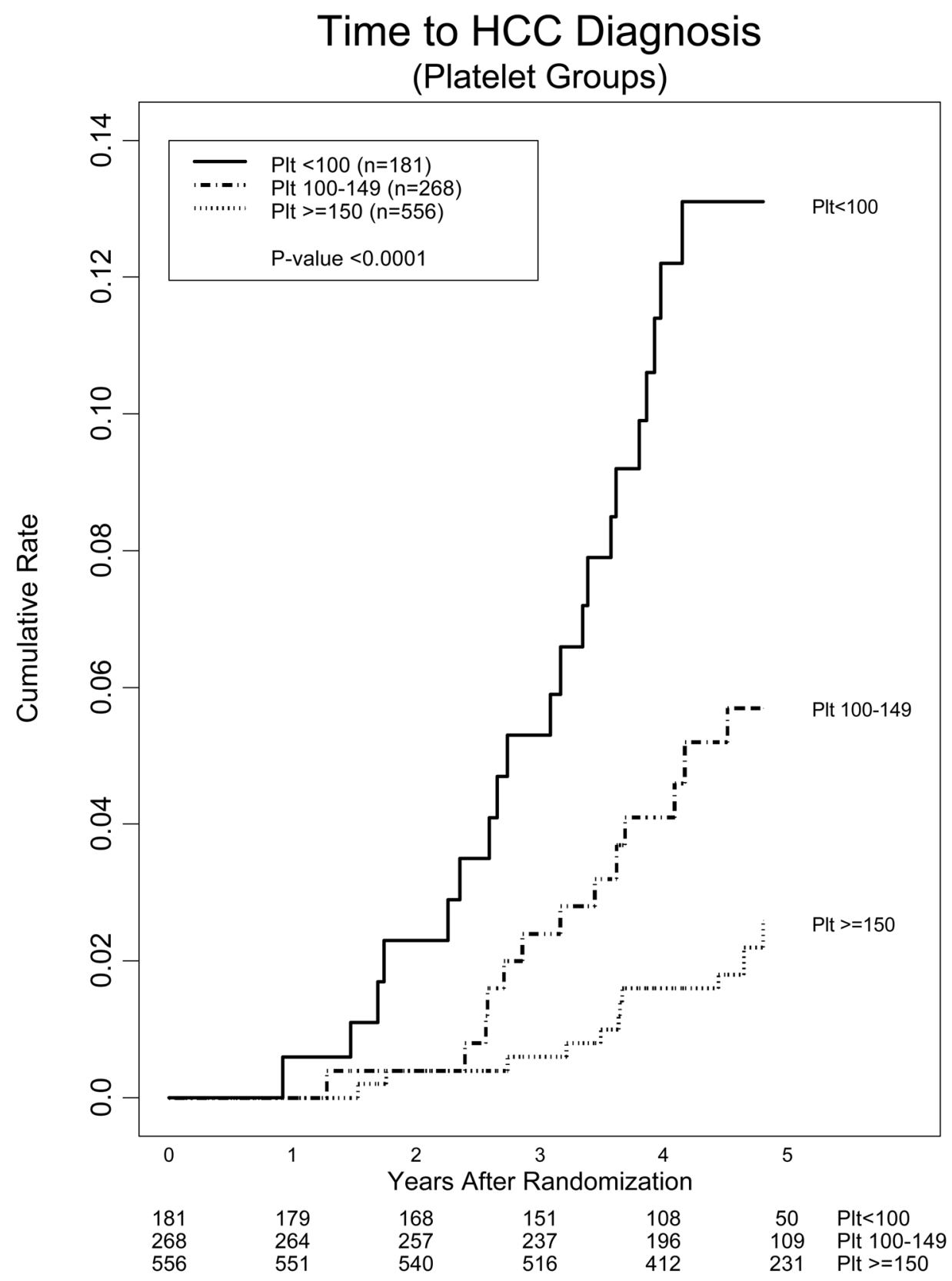

Figure 3.

Kaplan-Meier estimates of cumulative incidence of HCC (A) in patients with and without esophageal varices or cirrhosis and (B) in patients with baseline platelet (plt) count $<100$, $100-149$, and $>150 \times 1000 / \mathrm{mm}^{3}$ 


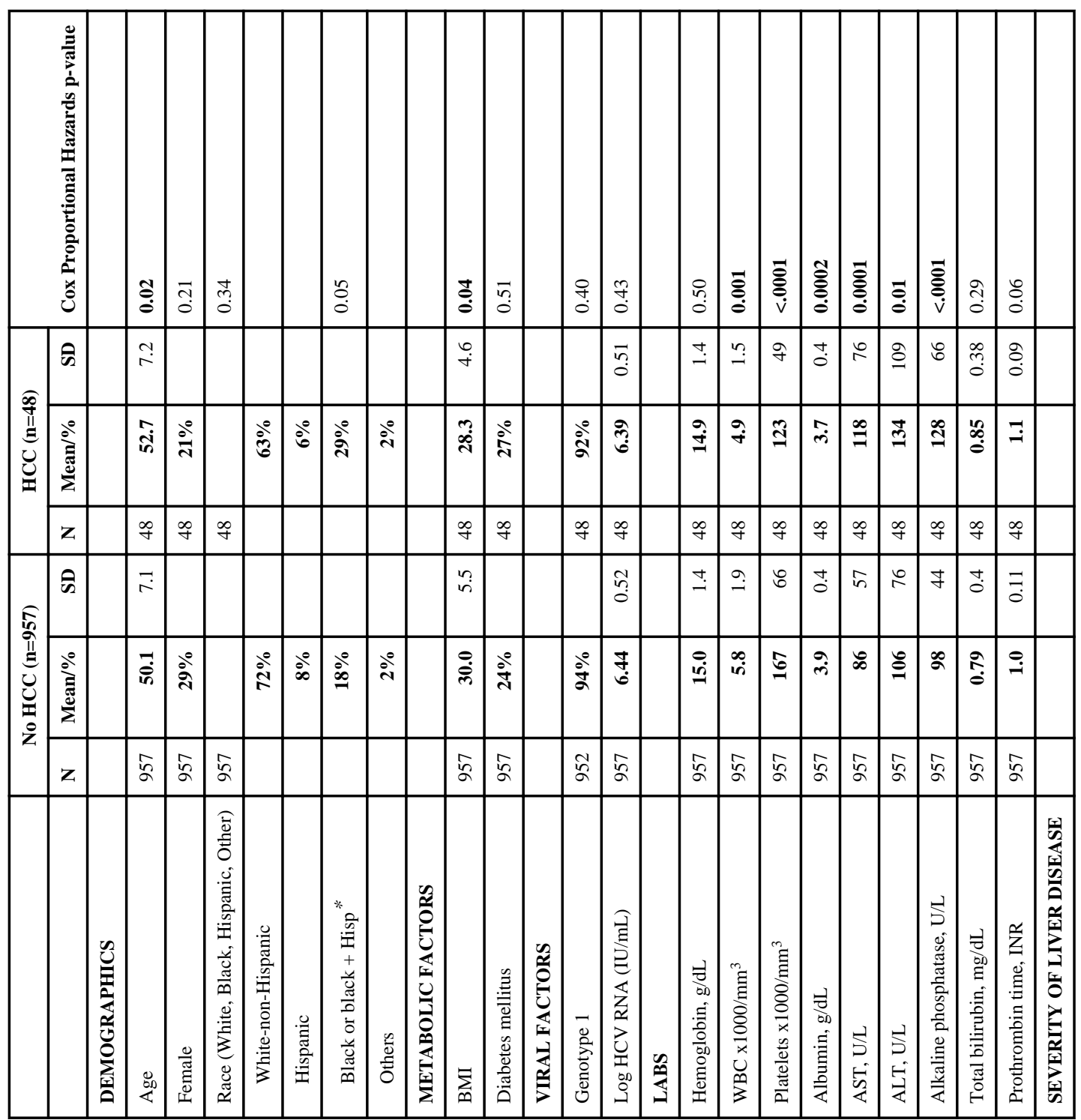




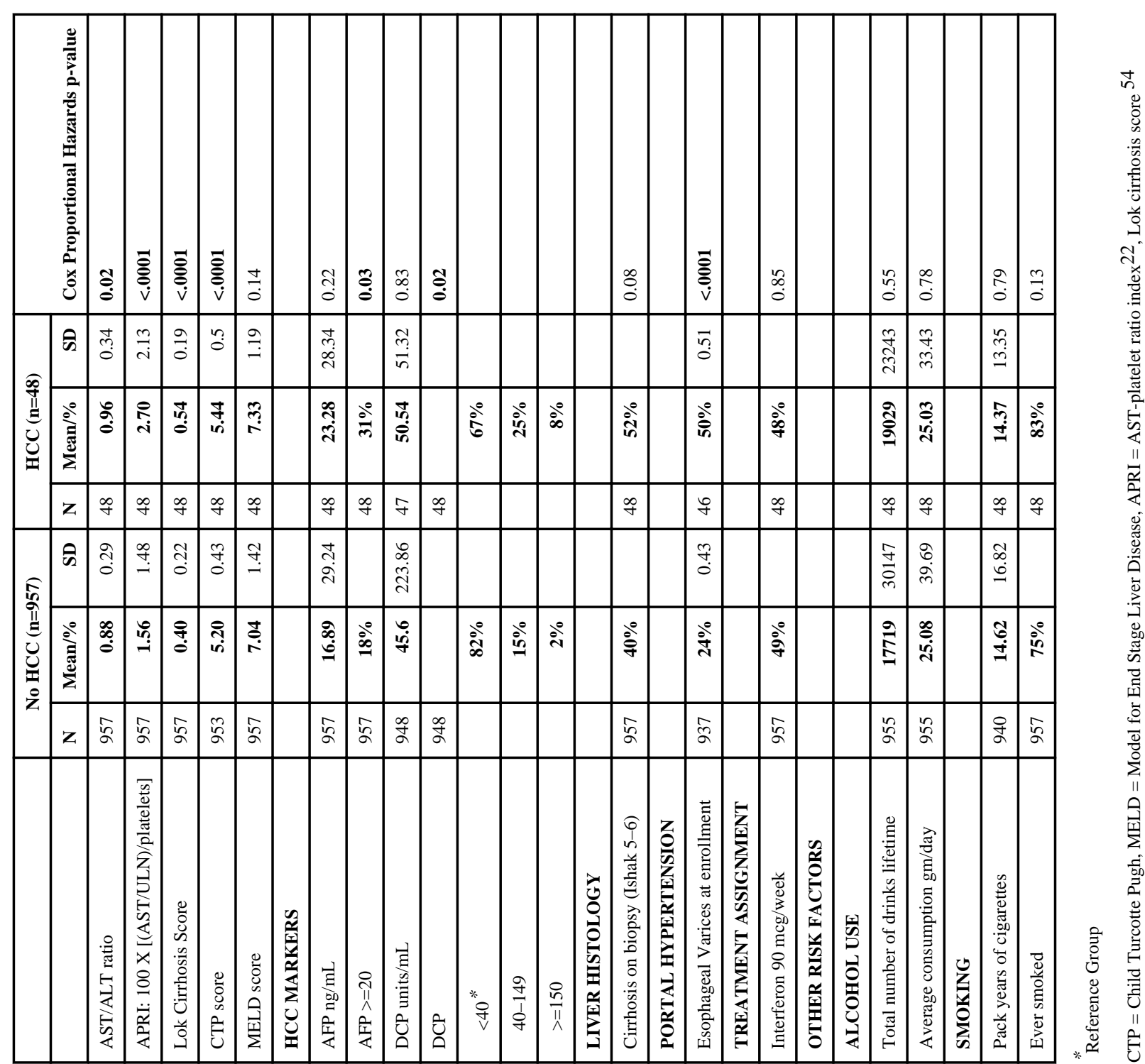




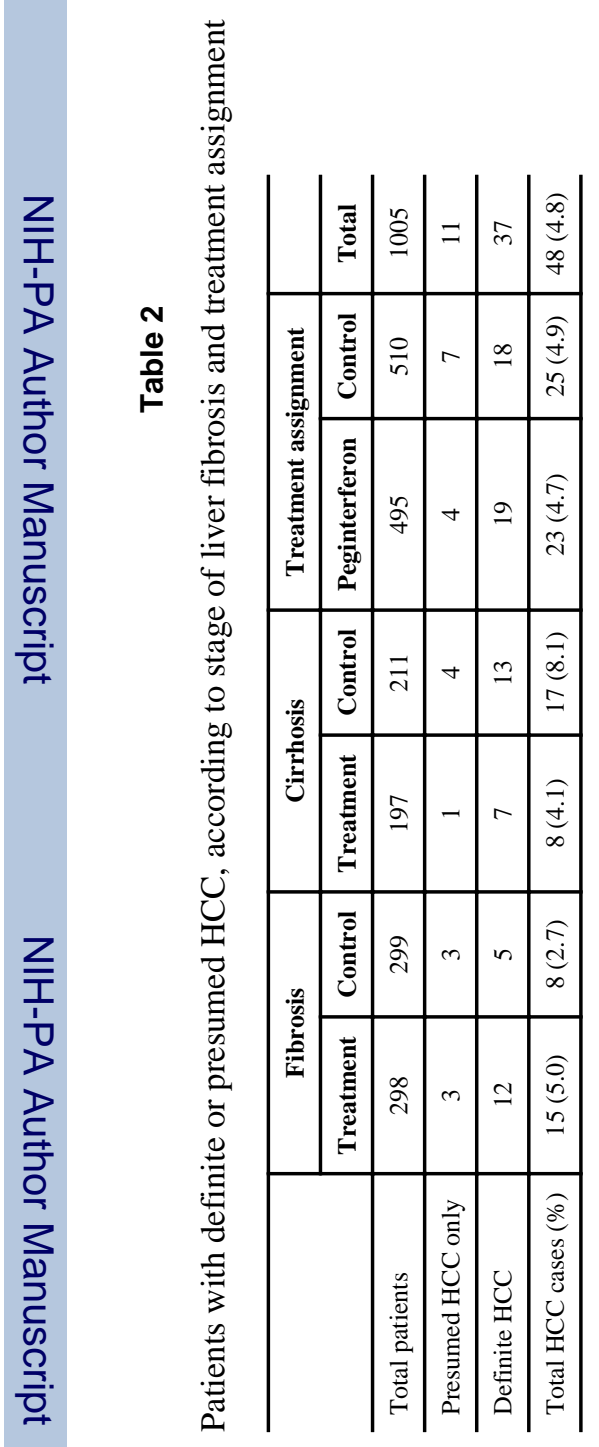

Gastroenterology. Author manuscript; available in PMC 2013 August 22. 


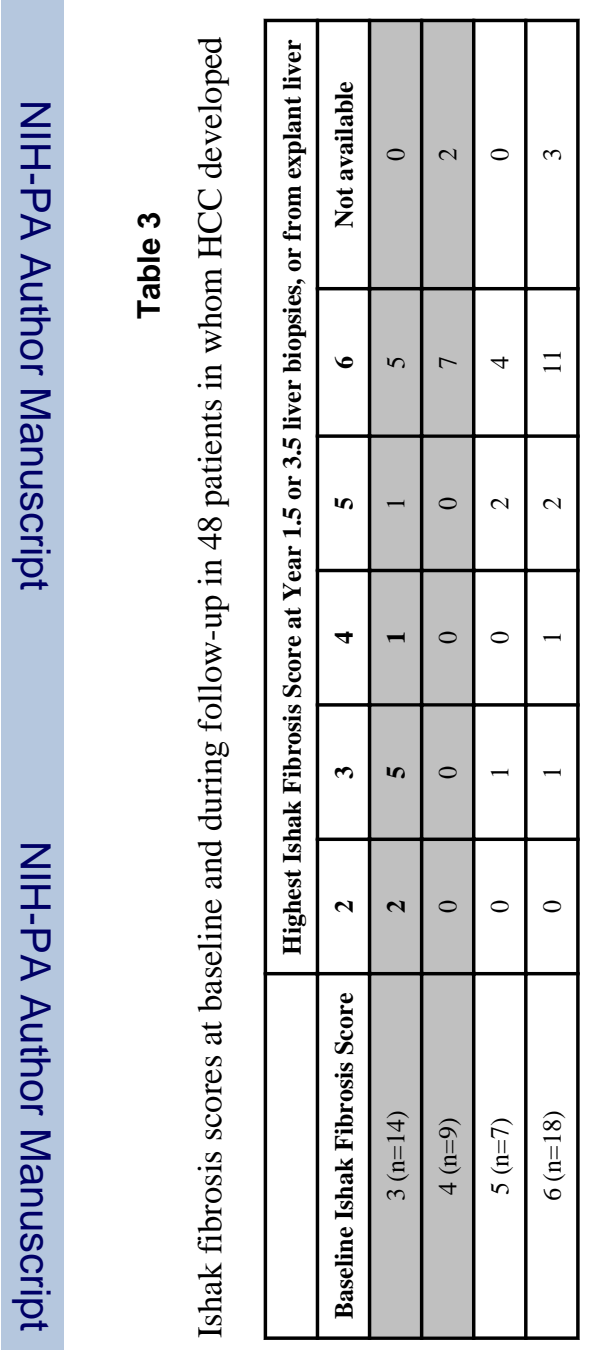

Gastroenterology. Author manuscript; available in PMC 2013 August 22. 


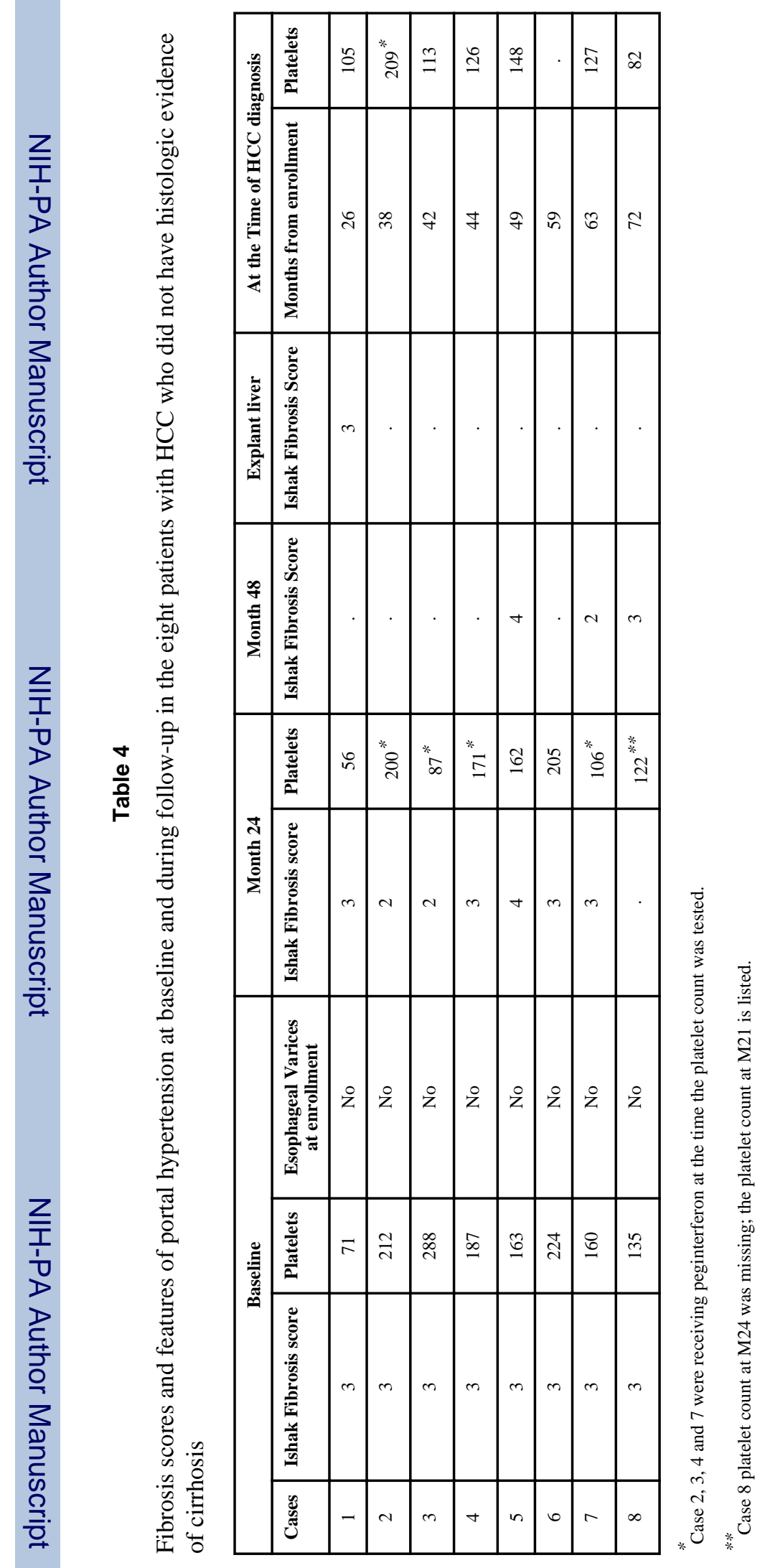

Gastroenterology. Author manuscript; available in PMC 2013 August 22. 


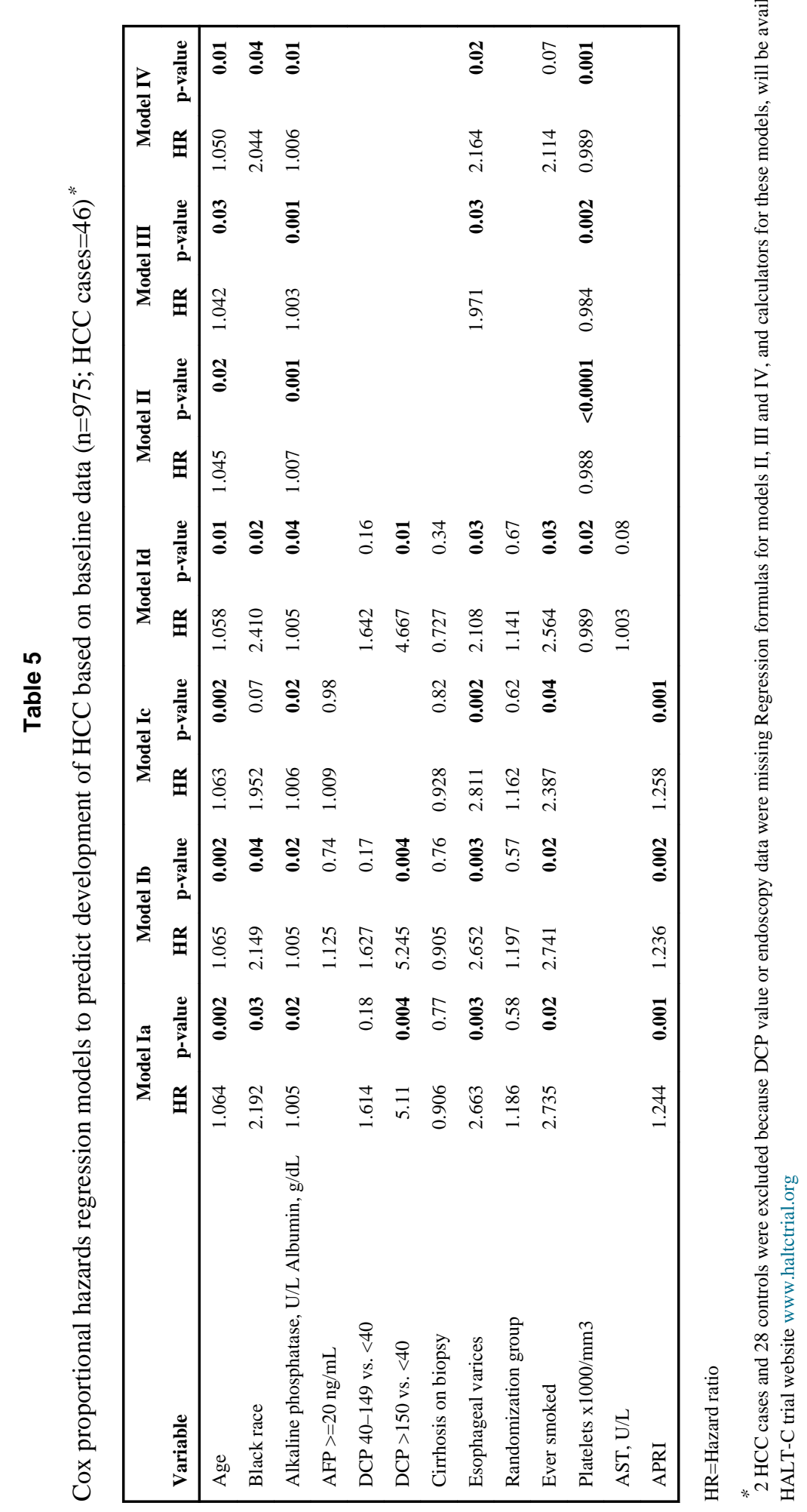

Gastroenterology. Author manuscript; available in PMC 2013 August 22. 